\title{
Den selection by the spiny lobster Panulirus argus: testing attraction to conspecific odors in the field
}

\author{
Gabrielle Nevitt ${ }^{1, *}$, N. Dean Pentcheff ${ }^{2}$, Kenneth J. Lohmann ${ }^{3}$, Richard K. Zimmer ${ }^{4}$ \\ ${ }^{1}$ Section of Neurobiology, Physiology and Behavior, University of California, Davis, California 95616, USA \\ ${ }^{2}$ Department of Biological Sciences, University of South Carolina, Columbia, South Carolina 29208, USA \\ ${ }^{3}$ Department of Biology CB\#3280, University of North Carolina, Chapel Hill, North Carolina 27510, USA \\ ${ }^{4}$ Department of Biological Sciences, University of California, Los Angeles, California 90095, USA
}

\begin{abstract}
The spiny lobster Panulirus argus is a model organism in laboratory studies of olfaction, but little is known about how these animals use odor cues in the field. Juvenile spiny lobsters aggregate in dens, a behavior that may be mediated via chemical attraction to conspecific odor cues. To test this hypothesis, we developed a submersible system capable of perfusing odors of live spiny lobsters into experimental den sites within a natural reef setting. Using this system, we tested the effect of conspecific odor on aggregative behavior by measuring the frequency of attraction of lobsters to den sites perfused with either conspecific odor or natural seawater. We found that juvenile spiny lobsters were attracted preferentially to dens perfused with conspecific odor: scented dens captured an average of 2.0 lobsters $\mathrm{den}^{-1} \mathrm{wk}^{-1}$ and control dens captured an average of 0.60 lobsters den ${ }^{-1} \mathrm{wk}^{-1}$. However, the distribution of the numbers of lobsters attracted to dens each day did not depart significantly from that predicted by a Poisson distribution, indicating that each capture was independent of all others. Our data thus suggest that the odor of conspecifics can act as an aggregation cue by spiny lobsters under field conditions, even in the absence of other sensory cues.
\end{abstract}

KEY WORDS: Aggregation · Lobster $\cdot$ Chemoreception $\cdot$ Olfaction

- Resale or republication not permitted without written consent of the publisher

\section{INTRODUCTION}

Palinurid lobsters often occupy crevices, holes or other refuges and share these den residences with conspecifics (Panulirus argus: Eggleston \& Lipcius 1992, Eggleston et al. 1992, Mintz et al. 1994; P. cygnus: Cobb 1981; P. interruptus: Zimmer-Faust \& Spanier 1987). Results from a variety of survey studies have indicated that even when den sites are plentiful, there tend to be more dens containing multiple lobsters than would be predicted by a random distribution of individuals (Lindberg 1955, Herrnkind et al. 1975, Kanciruk 1980, Zimmer-Faust \& Spanier 1987, Hunt et al. 1991, Spanier \& Almong-Shtayer 1992, MacDiarmid 1994). Moreover, California and Caribbean spiny lob-

*E-mail: ganevitt@ucdavis.edu sters ( $P$. interruptus and $P$. argus, respectively) show aggregative behavior in laboratory tests using artificial dens (Zimmer-Faust \& Spanier 1987, Ratchford \& Eggleston 1998). The collective evidence suggests that the presence or absence of a conspecific can be a significant factor in defining a preferred den site.

Den choice is probably influenced by several factors, including the physical features of the habitat, population density and behavioral interactions between individuals. In areas where lobsters are abundant, gregarious clustering within dens may facilitate detection of predators and their exclusion from dens (Cobb 1981, Zimmer-Faust et al. 1985, Eggelston et al. 1990, Eggleston \& Lipcius 1992). Occupancy of a den by several lobsters has also been shown to enhance survivorship (Eggleston \& Lipcius 1992), suggesting a clear benefit from aggregative behavior. 
The sensory cues that mediate aggregation have not been clearly established. Spiny lobsters Panulirus argus are highly chemosensitive (Reeder \& Ache 1980, Derby 2000), suggesting that chemical cues likely play a role in this behavior. In support of this hypothesis, Zimmer-Faust et al. (1985) suggested that, pheromonal or other conspecific, odor cues might enhance the preference of lobsters to choose particular den sites over others. For example, they have shown that under laboratory conditions the California spiny lobster $P$. interruptus is attracted to dens scented with conspecific odors but will avoid dens containing odors of recently killed lobsters. More recent laboratory studies of $P$. argus suggest that conspecific chemical attractants contribute to an ontogenetic shift in sociality among these animals (Ratchford \& Eggleston 1998). It has not been demonstrated, however, whether spiny lobsters will selectively occupy dens scented with conspecific odors under field conditions.

The goal of this study was to test the hypothesis that conspecific odors in the absence of other stimuli, such as sound (Moulton 1957, Mulligan \& Fischer 1977), could act as aggregation cues to freely behaving spiny lobsters Panulirus argus under field conditions. To test this hypothesis, we developed a submersible system capable of perfusing experimental den sites with odors of live $P$. argus within a natural reef setting. Using this system, we were able to test the effect of conspecific odor on aggregative behavior by measuring the frequency at which lobsters were attracted to den sites perfused with either conspecific odor or natural seawater.

\section{MATERIALS AND METHODS}

Study site. This study was conducted during May 1993 at Three Sisters Patch Reef located approx. $10 \mathrm{~km}$ southeast of Key Largo, Florida. This reef is $130 \mathrm{~m}$ long and 15 to $30 \mathrm{~m}$ wide. It is fairly isolated, and is surrounded by open sand and seagrass Thalassia testudinium beds that extend for hundreds of meters in all directions. The study was performed at this location as part of a larger investigation examining orientation mechanisms in Caribbean spiny lobsters Panulirus argus (Lohmann et al. 1995, Nevitt et al. 1995). Major features of the underwater topography and the study area are shown in Fig. 1.

Artificial dens and perfusion apparatus. Eight artificial dens were constructed from polyvinylchloride (PVC) pipes that were cut in half, lengthwise. Each den consisted of either 2 or 4 parallel pipe halves to fit existing crevices in the reef. Each pipe-half (Fig. 2) was $20 \mathrm{~cm}$ in diameter and $0.5 \mathrm{~m}$ in length. The pipe-halves were seasoned in salt water for approx. $1 \mathrm{wk}$ to remove

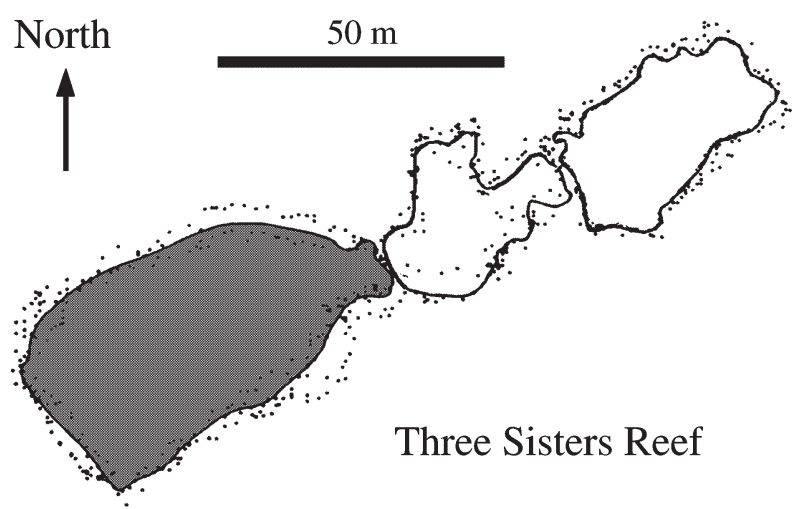

Fig. 1. Three Sisters Reef and vicinity $\left(25^{\circ} 01^{\prime} 46^{\prime \prime} \mathrm{N}\right.$, $80^{\circ} 23^{\prime} 53^{\prime \prime} \mathrm{W}$ ). Reef outlines (small dots) were mapped using a differential GPS receiver (see Nevitt et al. 1995). Maximum depth at this location is $6 \mathrm{~m}$. Artificial dens were deployed in filled area for this study

potentially toxic residues. They were then placed with their open sides facing downward and covered with coral rubble. Four pairs (experimental and control) of artificial dens were positioned on the reef in crevices chosen to mimic as closely as possible the shelter characteristics of natural lobster dens. All dens were placed at least $6 \mathrm{~m}$ apart.

Both male and female juvenile lobsters (carapace length, $\mathrm{CL} \leq 60 \mathrm{~mm}$ ) were captured from the reef using hand-held nets and tickle sticks (Lohmann et al. 1995, Nevitt et al. 1995). Following capture, lob-

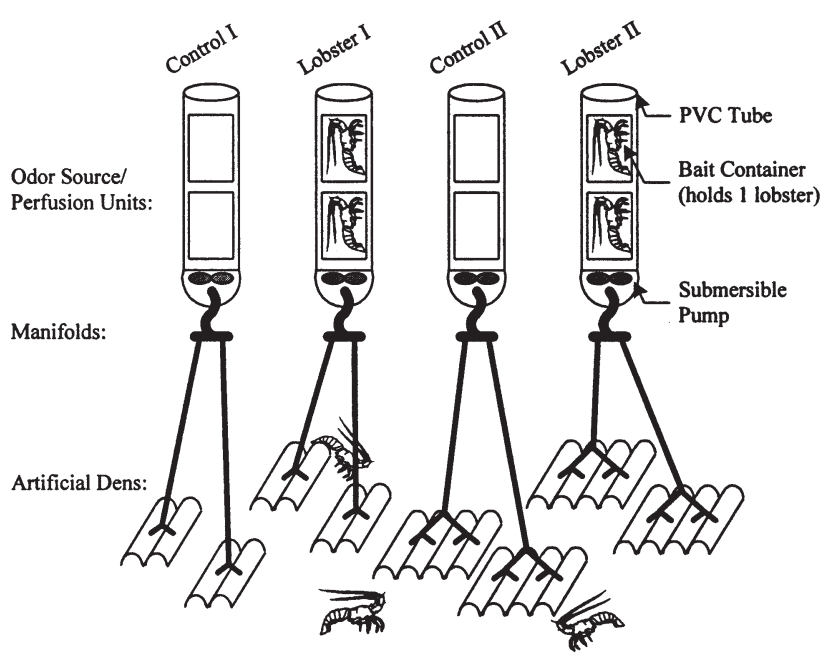

Fig. 2. Diagrammatic layout of perfusion system and artificial dens (not to scale). Submersible pumps mounted in PVC tube end-caps draw ambient seawater into open tube ends, through perforated bait containers, then out through manifolds to PVC pipe-halves acting as artificial dens. Each bait container held a spiny lobster Panulirus argus for lobsterscented treatments; bait containers were empty for unscented control treatments 
sters were individually confined to cylindrical, perforated, plastic bait-containers, $9 \mathrm{~cm}$ in diameter and $30 \mathrm{~cm}$ long. All manipulations were performed by SCUBA divers, thus lobsters were not brought to the surface for this transfer. Plastic bait-containers were inserted into 'odor-source tubes' made of PVC pipe approx. $1.5 \mathrm{~m}$ long and $10 \mathrm{~cm}$ in diameter. Odorsource tubes were constructed to accommodate 2 bait containers each. Four odor-source tubes were placed at a central location near the reef where dens were located; 2 odor-source tubes contained lobsters, while the other 2 tubes contained empty bait containers and supplied 'unscented' control seawater to dens as described below. Bait lobsters were replaced with newly captured lobsters every 1 to $3 \mathrm{~d}$ during the experiment. There was no mortality among the odorsource lobsters.

A submersible pumping system was installed in each odor-source tube to draw water past the bait lobsters (or past the empty bait containers for the control treatment) and out to the artificial dens. Small submersible bilge pumps (Rule, Model 24) were mounted in PVC caps on each odor-source tube. The in-current tube of each pump was threaded through a hole drilled in each cap. Hence, seawater entered through the open end of the tube, passed through the perforated bait containers and out through the pump. Each pump's ex-current tube was connected to a manifold made from $2 \mathrm{~cm}$ diam. PVC pipe, which supplied perfusion water through lengths of plastic tubing $(0.673 \mathrm{~cm}$ i.d.) at a rate of $\sim 1.5 \mathrm{l} \mathrm{min}^{-1}$ to each den. The perfusion tubing from the pumping site was subdivided at each den using a T-connection so that every pipe-half in the den received an equal supply.

Power for the pumps was provided by two $6 \mathrm{~V}$ gelcell batteries wired in parallel, contained in a customfabricated aluminum housing. To change the batteries each day without disrupting the odor-source tubes, it was necessary to use electrical connections between the pumps and the battery housing that could be attached and detached in situ. A 2-contact EO plug (Crouse-Hinds Joy Molded Products) connected each of 4 pumps to a 4 -socket EO receptacle mounted on the battery housing. All permanent electrical splices were waterproofed by potting in urethane (Devcon Flexane). After detaching the plugs at depth, the battery housing could be brought to the surface by a diver and then returned to the site with freshly charged batteries within a few minutes.
Treatment and analysis. Each morning divers censused the artificial dens for new arrivals. These lobsters were captured and removed from the patch reef. After each day's census, the odor treatments (lobster scent or unscented control seawater) for the dens were switched by swapping tubes at the manifolds. These experiments were run continuously for $15 \mathrm{~d}$.

To determine whether the odor treatment attracted lobsters, a G-test (Zar 1974) was used to compare the number of recruitment events per den for each sample day between odor and control treatments. Because odor treatments were switched between sample days and any new lobsters were removed from dens on each of the $15 \mathrm{~d}$ of the experiment, each occupancy event was considered to be independent.

To test for independence, we used a G-test to compare the distribution of the number of lobsters found in each den per day with the distribution predicted by a Poisson process (Zar 1974). Because the treatments (lobster or seawater control) could affect attraction rates, distributions for each treatment were considered separately.

\section{RESULTS}

Dens perfused with the odor of sub-adult conspecifics were significantly more effective at attracting Panulirus argus than dens that were perfused with unscented control seawater (Table 1). Individuals that were attracted to dens were predominantly medium to large juveniles (52 to $89 \mathrm{~mm} \mathrm{CL}$ ), and were never gravid. However, gravid lobsters were rarely observed on the reef at the time of this experiment.

Expressed as an average using a standardized recruitment measure used in lobster-trapping studies

Table 1. Incidence of Panulirus argus attraction to 8 artificial den sites at the Three Sisters Reef for $15 \mathrm{~d}$. Odor treatments (seawater passed over adult lobsters or control seawater) were switched daily, and perfused into dens continually. Dens were censused and cleared each morning. Total den-days: number of $1 \mathrm{~d}$ tests across all den sites; total lobsters attracted: sum of individual lobsters attracted throughout entire experiment; den-days with lobsters: number of den sites that attracted $\geq 1$ lobsters overnight; den-days without lobsters: number of den sites that failed to attract lobsters overnight. G-test of den-days with and without lobsters shows a significant difference between treatments $(G=4.51$, $\mathrm{df}=1, \mathrm{p}<0.035)$. Similarly, $G$-test of total number of lobsters attracted yields a significant difference between treatments $(G=6.52, \mathrm{df}=1, \mathrm{p}<0.01$; corrected for total number of den-days)

\begin{tabular}{|c|c|c|c|c|}
\hline \multirow{2}{*}{$\begin{array}{l}\text { Experimental } \\
\text { treatment }\end{array}$} & \multirow{2}{*}{$\begin{array}{c}\text { Total } \\
\text { den-days }\end{array}$} & \multicolumn{3}{|c|}{ Incidence of attraction } \\
\hline & & $\begin{array}{l}\text { Total lobsters } \\
\text { attracted }\end{array}$ & $\begin{array}{c}\text { Den-days } \\
\text { with lobsters }\end{array}$ & $\begin{array}{c}\text { Den-days } \\
\text { without lobsters }\end{array}$ \\
\hline Scented & 60 & 17 & 12 & 48 \\
\hline Control & 58 & 5 & 4 & 54 \\
\hline
\end{tabular}


(Heatwole et al. 1988), odor-perfused dens captured an average of 2.0 lobsters $\mathrm{den}^{-1} \mathrm{wk}^{-1}$ and control dens captured an average of 0.60 lobsters $\mathrm{den}^{-1} \mathrm{wk}^{-1}$. Because each den's odor treatment was switched every day, these results also indicate that the odor acts as a short-term, water-borne cue, and does not depend on a long-term accumulation of an odor cue on the rock floors or plastic walls of the dens.

Within each of the 2 treatments (scented and unscented control seawater), we examined the distributions of the number of lobsters that were attracted to the dens. If lobsters arrived in groups or if the presence of an initial individual enhanced the probability of more arrivals during a $1 \mathrm{~d}$ test period, then there would be more dens with $\geq 2$ lobsters than would be expected by chance (Poisson) distribution. Fig. 3 shows that the distribution of lobsters within dens did not depart significantly from that predicted by a Poisson distribution for either scented (Fig. 3A) or unscented (Fig. 3B) treatments. This result indicates that each arrival was independent of all others; hence, there was no tendency of lobsters to recruit in groups for either treatment.

\section{DISCUSSION}

The results presented here demonstrate that juvenile spiny lobsters Panulirus argus will recruit to artificial dens scented with conspecific odors. Because the experimental treatments were switched daily, our findings suggest that the conspecific odor cue is likely to be ephemeral and water-borne, rather than a persistent cue that is absorbed by the den surfaces. Although the specificity of this cue was not directly examined in this field study, this result is also consistent with laboratory studies suggesting that a water-borne conspecific odor cue mediates aggregation (Zimmer-Faust \& Spanier 1987). The chemical attraction takes effect rapidly (within $1 \mathrm{~d}$ ). Similarly, when the odor source is removed, the effect of the odor disappears within $1 \mathrm{~d}$. This result thus supports the hypothesis that a conspecific odor acts as a signal of current den occupancy rather than as a persistent marker indicating prior occupancy of a specific den site. Moreover, within our $1 \mathrm{~d}$ test periods, the attraction of each lobster to a given den was an independent event. Our data therefore indicate that the odor of conspecifics promotes gregarious den occupancy by lobsters under field conditions, even in the absence of other sensory information.

A useful comparison can be made between catch rates in our experiment (where odor is the only conspecific cue) and catch rates of trapping studies that use live lobster 'shorts' (sub-legal sized lobsters, $<76 \mathrm{~mm} \mathrm{CL}$ ) as bait. Bait experiments present wild lobsters with a full suite of olfactory, visual, tactile, and
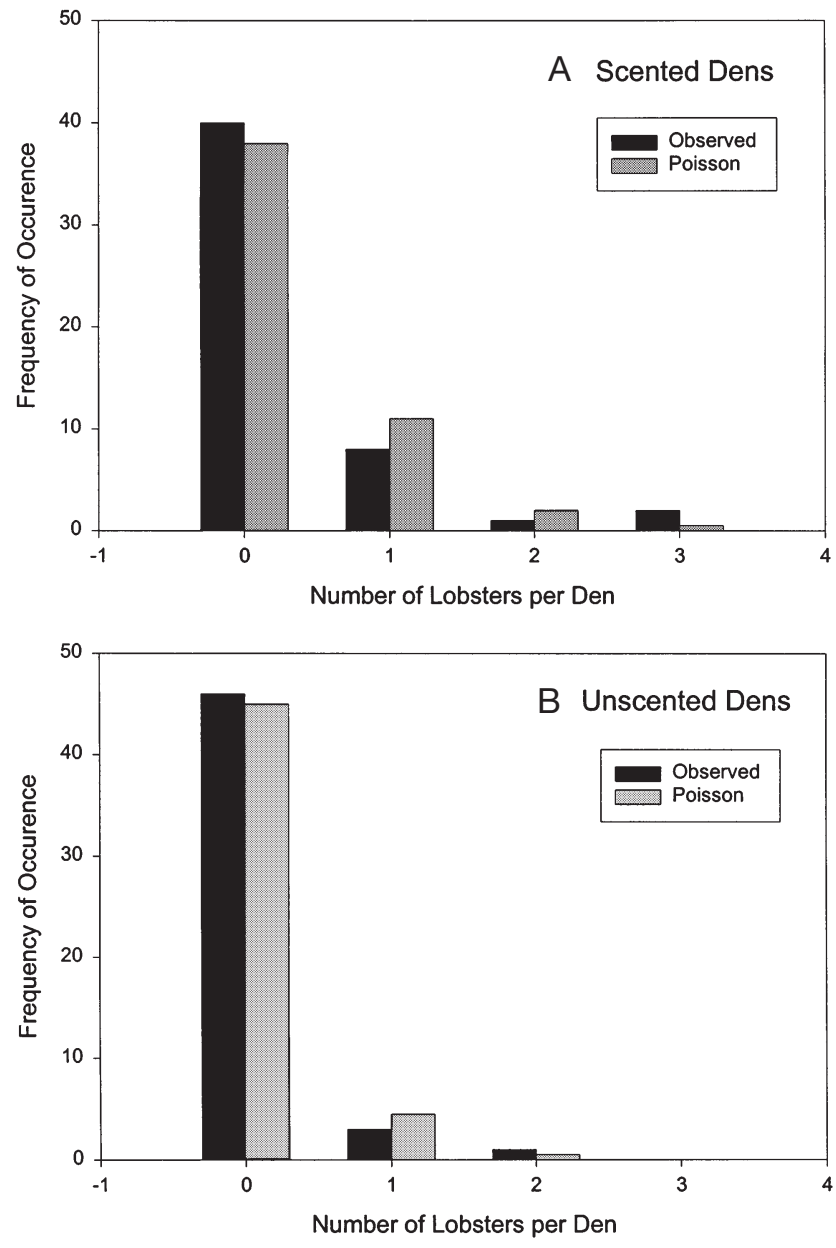

Fig. 3. Panulirus argus. Comparison of observed and expected Poisson distributions of numbers of arrivals to test for significant interaction between the attraction of lobsters during the $1 \mathrm{~d}$ trials. G-test shows no significant departure from the distribution expected by random chance for both (A) lobsterscented and (B) unscented control dens (lobster-scented dens $G=2.512, \mathrm{df}=3, \mathrm{p}=0.473$; unscented control dens $G=0.829$, $\mathrm{df}=2, \mathrm{p}=0.661)$. Hence, attraction of each lobster was independent from all others

auditory signals that might be attractive to them. However, the catch rates in our study are similar to or even higher than catch rates that have been reported from such studies. For example, in our experiments, odorperfused dens captured an average of 2.0 lobsters $\mathrm{den}^{-1} \mathrm{wk}^{-1}$ and control dens captured an average of 0.6 lobsters $\mathrm{den}^{-1} \mathrm{wk}^{-1}$. Results from trapping studies conducted in the Florida Keys during early summer 1983 reported a capture rate of 0.77 lobsters trap $^{-1}$ $w^{-1}$ for traps baited with 2 'shorts' versus 0.35 lobsters trap $^{-1} \mathrm{wk}^{-1}$ for empty traps (Heatwole et al. 1988). Further experiments performed in the Florida Keys during May through August 1985 showed capture rates of 2.4 lobsters trap ${ }^{-1} \mathrm{wk}^{-1}$ for traps baited with 3 'shorts' versus 0.84 lobsters $\operatorname{trap}^{-1} \mathrm{wk}^{-1}$ for unbaited traps 
(Heatwole et al. 1988). The ability of the odor cue alone to generate recruitment rates comparable to those generated by the array of sensory cues provided by live lobsters suggests that olfaction may play a key role in initiating aggregation under natural conditions, at least for subadult $P$. argus.

\section{Conspecific odor cues as an indicator of den quality}

The fact that spiny lobsters Panulirus argus are attracted to dens scented with conspecific odors suggests that lobsters use odor cues to find appropriate shelter. We hypothesize that, in addition to specific physical features of the den site, conspecific odors provide lobsters with a means of assessing the quality of the potential shelter. From a physical standpoint, highquality dens provide a refuge from predation (Herrnkind \& Butler 1986, Mintz et al. 1994), storm surge, or protection during molting (Lipcius \& Herrnkind 1982). Studies with $P$. interruptus and $P$. argus have established that lobsters prefer dens that have shaded cover and multiple entrances and ways of escape (Spanier \& Zimmer-Faust 1988, Eggleston et al. 1990). Further studies by Butler \& Herrnkind (1997) have shown that augmenting natural shelter with appropriately designed artificial structures can increase local recruitment of $P$. argus. Aggregating within dens may further increase den quality by enhancing predator exclusion from dens and thus the protective capacity of the shelter. Within a den, lobsters position themselves so that their antennae protrude from multiple openings. This behavior is considered to be a form of antipredator vigilance (Kanciruk 1980, Cobb 1981, Zimmer-Faust \& Spanier 1987, Eggleston et al. 1990). A similar form of anti-predator behavior is observed during offshore migrations in which lobsters travel in defensive queues. If a predator approaches, lobsters can quickly rearrange themselves into a defensive circle with antennae facing outwards ready to inflict injury (Herrnkind \& McLean 1971). P. argus has recently been shown to localize mechanosensory stimuli and direct their antennal movements towards a perceived predator (Wilkens et al. 1996). Taken together, these observations suggest that the presence or absence of conspecifics is likely to be as important as physical features in assessing the quality of a potential den site.

Results from field studies with artificial shelters ('casitas') on mortality rates of Panulirus argus further this argument by showing direct relationships between shelter size, gregarious behavior and lobster survivorship (Eggleston et al. 1990, 1992, Eggleston \& Lipcius 1992, Mintz et al. 1994). In these investigations, small and medium casitas had highest survival levels for small (35 to $45 \mathrm{~mm} \mathrm{CL}$ ) and medium (46 to $56 \mathrm{~mm} \mathrm{CL}$ ) lobsters (Eggleston et al. 1990). Eggleston et al. found that juvenile lobsters chose dens largely by the presence or absence of conspecifics and that gregarious behavior extended the minimum size range of lobsters that could survive in large shelters (Eggleston \& Lipcius 1992). $P$. argus tended to select large shelters in areas where conspecific abundance was high. Large shelters provided for larger aggregations, but if lobster abundance was low, then predators would move into large shelters as well (Eggleston \& Lipcius 1992, Mintz et al. 1994). Low lobster abundance reduced the potential for gregarious behavior, thereby limiting the protective capacity of a shelter (Eggleston \& Lipcius 1992). Based on these results, Eggleston \& Lipcius suggested that conspecifics (as well as shelters) could be viewed as a limiting resource (see also Butler \& Herrnkind 1997, Childress \& Herrnkind 1997). It stands to reason that spiny lobsters would be highly tuned to conspecific odor cues that might alert them to this resource. Likewise, odor cues could assist lobsters in avoiding dens where predators might be hiding (Zimmer-Faust et al. 1985).

Our data suggest that conspecific odors are likely to aid spiny lobsters Panulirus argus in locating occupied dens. Field studies investigating this behavior are lacking, but observations by other researchers are consistent with the hypothesis that palinurid lobsters use conspecific odor cues to locate dens opportunistically. For example, Trendall \& Bell (1989) monitored movement patterns of individual rock lobsters $P$. ornatus near Australia. They found that occupancy patterns were unpredictable and opportunistic. On average, $60 \%$ of all possible den sites were vacant and even the best dens (defined as dens which were at times occupied by $\geq 3$ lobsters) remained unoccupied $20 \%$ of the time. In this population, home den sites were not spatially discrete, since occupancy changed from day to day. The picture that emerges is that conspecific odor cues could potentially advertise the occupancy status of a particular den site and thus serve as an indicator of its immediate quality as a place to shelter for the day. Further experiments testing the specificity of this attraction are needed to confirm this hypothesis.

\section{Potential role for chemical communication}

Besides serving as a general aggregation cue, conspecific odors are likely to communicate chemical information between individuals. In a recent study, Ratchford \& Eggleston (1998) used laboratory Y-maze experiments to examine whether Panulirus argus showed an ontogenetic shift in attraction to conspecific odors. Their results suggest that an attraction for con- 
specific odors begins only after $P$. argus has reached $15 \mathrm{~mm}$ CL in body size. While reproductive individuals were not tested in this study, a number of field investigations have shown that cohabitation varies seasonally with molting and reproduction (Davis 1977, Lipcius \& Herrnkind 1982, Hunt et al. 1991). In an intensive 3 yr study of spiny lobsters Jasus edwardsii in patch reefs in NE New Zealand, MacDiarmid $(1991,1994)$ found that cohabitation varied with size, age and sex: subjuveniles typically were found aggregated in a few large groups, mainly in shallow water with no consistent seasonal patterns of cohabitation. Large, reproductive males, however, were often solitary and showed seasonal trends in cohabitation: during the breeding season, lobsters tended to be distributed haphazardly in the habitat, whereas in the non-breeding season, reproductive males were gregarious (highly clumped). MacDiarmid also found that during the breeding season $73 \%$ of the post-molt pre-ovigerous (soon to mate) females cohabited with a reproductive male.

Interestingly, MacDiarmid's (1994) study also provides evidence for den selection by females, because some males had as many as 16 cohabiting females while most males (59\%) did not have any. More females were found in dens with the biggest males. (Males of 140 to $149 \mathrm{~mm}$ CL had an average of $2 \pm 0.52$ SE females, while males $\geq 180 \mathrm{~mm}$ CL had $4.8 \pm 1.27 \mathrm{SE}$ cohabiting females; MacDiarmid 1994). Mature males are aggressive towards one another in this species (MacDiarmid 1989) and females move between males (MacDiarmid 1991), suggesting that males defend shelters, not harems (MacDiarmid 1994). It is thus possible that the presence of female odor may contribute to the quality of that shelter from the point of view of females assessing potential mates.

Although comparable data are not available for Panulirus argus, MacDiarmid's combined work suggests that understanding the mechanisms underlying den selection and gregarious behavior in palinurid lobsters and other decapod crustaceans is a rich area for future experimental study in the field in terms of chemical communication. Recent laboratory Y-maze studies of mature American lobsters Homarus americanus have shown clear sex biases in shelter preference. Females preferred male-occupied shelters to empty shelters, and released 4 times as much urine as they approached shelters as they did during an equal time in isolation (Bushmann \& Atema 1997). In our experiments, we baited dens exclusively with the scents of juvenile lobsters. Baiting dens with the scent of reproductive males, for example, might influence the amount or type of female attraction that is observed. Alternatively, baiting dens with the odor of reproductive females might tend to attract smaller reproductive males, which are thought to move between shelters in search of unguarded reproductive females in other palinurids (MacDiarmid 1991).

Panulirus argus in particular offers many advantages for future behavioral work. This species has been used extensively in laboratory studies of behavioral discrimination of odorants, and neural coding of odor quality and intensity (see Derby 2000 for review). For example, behavioral studies show that $P$. argus can distinguish between odor mixtures and components and is able to learn to discriminate odors in the laboratory (Fine-Levy \& Derby 1992, Lynn et al. 1994, Cromarty \& Derby 1997). While the specific odorants or pheromone compounds involved in den discrimination have not been identified, the technique we describe is ideally suited for testing chemical cues which could potentially be mediating den choice in palinurids in field situations. Field investigations incorporating studies on seasonal shifts and sex-specific differences in olfactory-mediated behavior should be addressed. Combining such studies with molecular and physiological investigation is approachable in this system, and will yield fascinating avenues of future research.

Acknowledgements. The authors gratefully acknowledge the logistical support provided by the NOAA National Undersea Research Center in Key Largo, particularly by Dave Ward, Tom Potts, and Steve Miller. We are grateful for the financial support of the National Undersea Research Program for this project, as well as support from the National Science Foundation Grants IBN 92-22225 to R.K.Z. and D. S. Wethey and IBN 93-20702 to R. Roberts, T. Takahashi and G. Nevitt.

\section{LITERATURE CITED}

Bushmann PJ, Atema J (1997) Shelter sharing and chemical courtship signals in the lobster Homarus americanus. Can J Fish Aquat Sci 54:647-654

Butler MJ, Herrnkind WF (1997) A test of recruitment limitation and the potential for artificial enhancement of spiny lobster (Panulirus argus) populations in Florida. Can J Fish Aquat Sci 54:452-463

Childress MJ, Herrnkind WF (1997) Den sharing by juvenile Caribbean spiny lobsters (Panulirus argus) in nursery habitat: cooperation or coincidence? Mar Freshw Res 48: $751-758$

Cobb JS (1981) Behavior of the Western Australian spiny lobster, Panulirus cygnus George, in the field and laboratory. Aust J Mar Freshw Res 32:399-409

Cromarty SI, Derby CD (1997) Multiple excitatory receptor types on individual olfactory neurons: implications for coding of mixtures in the spiny lobster. J Comp Physiol 180:481-449

Davis GE (1977) Effects of recreational harvest on a spiny lobster, Panulirus argus, population. Bull Mar Sci 27:223-236

Derby CD (2000) Learning from spiny lobsters about chemosensory coding of mixtures. Physiol Behav 69(1): 203-209

Dusenbery DB (1992) Sensory ecology: how organisms acquire and respond to information. Freeman Press, New York 
Eggleston DB, Lipcius RN (1992) Shelter selection by spiny lobster under variable predation risks, social conditions, and shelter size. Ecology 73:992-1011

Eggleston DB, Lipcius RN, Miller DL, Coba-Cetina L (1990) Shelter scaling regulates survival of juvenile Caribbean spiny lobster Panulirus argus. Mar Ecol Prog Ser 62: 79-88

Eggleston DB, Lipcius RN, Miller DL (1992) Artificial shelters and survival of juvenile Caribbean spiny lobster Panulirus argus - spatial, habitat, and lobster size effects. Fish Bull US 90:691-702

Fine-Levy JB, Derby CD (1992) Behavioral discrimination of binary mixtures and their components: effects of mixture interactions on coding of stimulus intensity and quality. Chem Senses 17:307-323

Heatwole DW, Hunt JH, Kennedy FS Jr (1988) Catch efficiencies of live lobster decoys and other attractants in the Florida spiny lobster fishery. Fla Mar Res Publ 44

Herrnkind WF, Butler MJ (1986) Factors regulating postlarval settlement and juvenile microhabitat use by spiny lobsters Panulirus argus. Mar Ecol Prog Ser 34:23-30

Herrnkind WF, McLean R (1971) Field studies of homing, mass emigration and orientation in the spiny lobster Panulirus argus. Ann NY Acad Sci 188:359-377

Herrnkind WF, Vanderwalker JA, Barr L (1975) Population dynamics, ecology and behavior of spiny lobsters, Panulirus argus, of St. John, U.S.V.I. IV. Habitation, patterns of movement and general behavior. Bull Nat Hist Mus Los Ang 20:31-45

Hunt JH, Matthews TR, Forcucci D, Hedin BS, Bertelsen RD (1991) Management implications of trends in the population dynamics of the Caribbean spiny lobster, Panulirus argus, at Long Key National Marine Sanctuary. NOAA US Dep Commerce, Office Ocean Cstl Res, Sanctuary Prog Div Final Rep

Kanciruk P (1980) Ecology of juvenile and adult Palinuridae (spiny lobsters). In: Cobb JS, Phillips BF (eds) The biology and management of lobsters, Vol 2. Physiology and behavior. Academic Press, New York, p 59-92

Lindberg RG (1955) Growth, population dynamics, and field behavior in the spiny lobster, Panulirus interruptus (Randall). Univ Calif Publs Zool 59:157-247

Lipcius RN, Herrnkind WF (1982) Molt cycle alterations in behavior, feeding and diet rhythms of a decapod crustacean, the spiny lobster Panulirus argus. Mar Biol 68: $241-252$

Lohmann KJ, Pentcheff ND, Nevitt GA, Stetten GD, ZimmerFaust RK, Jarrard HE, Boles LC (1995) Magnetic orientation of spiny lobsters in the ocean: experiments with undersea coil systems. J Exp Biol 198:2041-2048

Lynn WH, Meyer EA, Peppiant CE, Derby CD (1994) Percep-

Editorial responsibility: Joseph Pawlik,

Wilmington, North Carolina, USA tion of odor mixtures by the spiny lobster, Panulirus argus Chem Senses 19:331-347

MacDiarmid AB (1989) Size at onset of maturity and size dependent reproductive output of female and male spiny lobsters Jasus edwardsii (Hutton, 1875, Decapoda, Palinuridae) in New Zealand. Mar Biol 103:303-310

MacDiarmid AB (1991) Seasonal changes in depth, distribution, sex ratio and frequency of the spiny lobster Jasus edwardsii, on a coastal reef in northern New Zealand. Mar Ecol Prog Ser 70:129-141

MacDiarmid AB (1994) Cohabitation in the spiny lobster Jasus edwardsii (Hutton, 1875). Crustaceana 66:341-355

Mintz JD, Lipcius RN, Eggelston DB, Seebo MS (1994) Survival of juvenile Caribbean spiny lobster: effects of shelter size, geographic location and conspecific abundance. Mar Ecol Prog Ser 112:255-266

Moulton JM (1957) Sound production in the spiny lobster Panulirus argus (Latreille). Biol Bull 113:286-295

Mulligan BE, Fischer RB (1977) Sounds and behavior of the spiny lobster Panulirus argus (Latreille, 1804) (Decapoda, Palinuridae). Crustaceana 32:185-199

Nevitt GA, Pentcheff ND, Lohmann KJ, Zimmer-Faust RK (1995) Evidence for hydrodynamic orientation by spiny lobsters in a patch reef environment. J Exp Biol 198: 2049-2054

Ratchford SG, Eggleston DB (1998) Size- and scale-dependent chemical attraction contribute to an ontogenetic shift in sociality. Anim Behav 56:1027-1034

Reeder PB, Ache BW (1980) Chemotaxis in the Florida spiny lobster, Panulirus argus. Anim Behav 28:831-839

Spanier E, Almog-Shtayer G (1992) Shelter preference in the Mediterranean slipper lobster: effects of physical properties. J Exp Mar Biol Ecol 164:103-116

Spanier E, Zimmer-Faust RK (1988) Some physical properties of shelter that influence den preference in spiny lobsters. J Exp Mar Biol Ecol 121:137-149

Trendall J, Bell S (1989) Variable patterns of den habitation by the ornate rock lobster, Palinurus ornatus, in the Torres Strait. Bull Mar Sci 45:564-573

Wilkens LA, Schmitz B, Herrnkind WF (1996) Antennal responses to hydrodynamic and tactile stimuli in the spiny lobster Panulirus argus. Biol Bull 191:187-198

Zar JH (1974) Biostatistical analysis. Prentice-Hall, Englewood Cliffs, NJ

Zimmer-Faust RK, Spanier E (1987) Gregariousness and sociality in spiny lobsters: implications for den habitation. J Exp Mar Biol Ecol 105:57-71

Zimmer-Faust RK, Tyre JE, Case JF (1985) Chemical attraction causing aggregation in the spiny lobster, Panulirus interruptus (Randall), and its probable ecological significance. Biol Bull 169:106-118

Submitted: February 25, 2000; Accepted: April 11, 2000

Proofs received from author(s): August 14, 2000 